Article

\title{
Spatial and Behavioral Thermal Adaptation in Net Zero Energy Buildings: An Exploratory Investigation
}

\author{
Shady Attia \\ Department UEE, Faculty of Applied Sciences, Sustainable Building Design Lab, Université de Liège, \\ 4000 Liège, Belgium; shady.attia@uliege.be
}

Received: 21 August 2020; Accepted: 23 September 2020; Published: 25 September 2020

\begin{abstract}
Climate responsive design can amplify the positive environmental effects necessary for human habitation and constructively engage and reduce the energy use of existing buildings. This paper aims to assess the role of the thermal adaptation design strategy on thermal comfort perception, occupant behavior, and building energy use in twelve high-performance Belgian households. Thermal adaptation involves thermal zoning and behavioral adaptation to achieve thermal comfort and reduce energy use in homes. Based on quantitative and qualitative fieldwork and in-depth interviews conducted in Brussels, the paper provides insights on the impact of using mechanical systems in twelve newly renovated nearly- and net-zero energy households. The article calls for embracing thermal adaptation as a crucial design principle in future energy efficiency standards and codes. Results confirm the rebound effect in nearly zero energy buildings and the limitation of the current building energy efficiency standards. The paper offers a fresh perspective to the field of building energy efficiency that will appeal to researchers and architects, as well as policymakers.
\end{abstract}

Keywords: rebound effect; passive design; thermal zoning; occupant behavior; energy sufficiency; affluence

\section{Introduction}

Thermal adaptation is an old bioclimatic design principle that was found in vernacular and traditional architecture. Instead of installing a mechanical system for heating or cooling, occupants and the buildings acted as the thermal system [1]. Thermal adaptation is a design principle that involves two main strategies. The first strategy involves spatial thermal zoning; in other words, compartmentalization. Thermal zoning allows the temporal use of spaces depending on comfort needs. A building is divided into separate thermal zones where occupants can select the most comfortable zone and control the comfort conditions through passive or/and active systems [2]. Careful thermal zoning effectively reduces the heating or cooling energy demand in the occupied spaces [3]. The second strategy involves occupant behavioral changes and traditions. People will adapt their occupancy patterns and comfort expectations depending on the season and engage in social and cultural practices that improve the thermal quality of occupied spaces. Behavioral habits and activities such as gathering, eating, changing clothes, opening windows, etc., will be adapted, concentrated, and localized depending on the availability of heating or cooling energy sources [4]. Thus, vernacular architecture worldwide displays a remarkable understanding and adoption of the thermal adaptation principle [5].

Today, with the use of Heating, Ventilation, and Air Conditioning (HVAC) systems in most buildings, the energy-use intensity exceeds most energy efficiency standards requirements. Scientists and construction professionals are engaged in closing the energy performance gap and increase the energy efficiency of renovated and newly constructed buildings [6]. The same applies to high-performance buildings, including Passive House (PH) certified buildings and nearly- and net-zero energy buildings. 
At the same time, another trend influences building energy-use reduction targets. Average homes are becoming more spacious, and the floor area is increasing by roughly $3 \%$ per year, which is a remarkably faster rate [7]. As shown in Figure 1, the rooms per person are significantly high. According to Eurostat, most EU countries have increased the number of rooms per person since $1990[8,9]$.

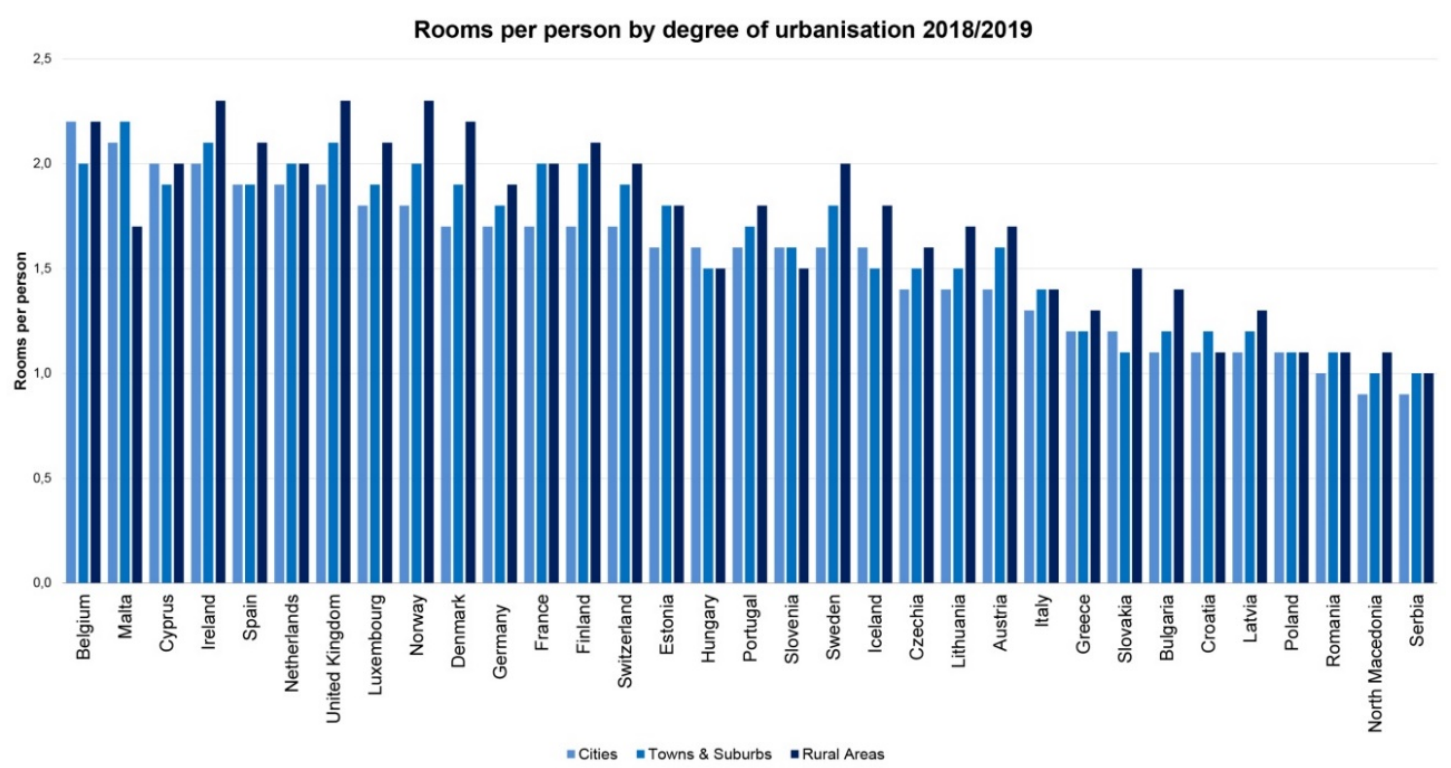

Figure 1. Rooms per person by degree of urbanization 2018/2019 [8].

Belgium is topping the list at 2.2 rooms per capita, which is equivalent to 70 square meters. Despite the significant energy-use intensity decrease in renovated and newly constructed households, the overall energy use of the building sector remains high. Belgium is one of the earliest countries in the EU Zone that introduced nearly- and net-zero energy building (nZEB and NZEB) concepts [10]. However, the highest income earners live in recently built or renovated housing that is large, which tends to improve the energy efficiency per square meter but increases the total energy use per capita [11]. The increasing trend of the higher building energy footprint of a high-income individual is not only found in Belgium but can be found worldwide [12].

Despite the improvements in the energy efficiency of high-performance buildings, the study of occupants' thermal adaptation and behavior remains mostly unaddressed, private, and scientifically not studied. The work of the International Energy Agency (IEA), namely Annex 66 and Annex 79, on occupant behavior in buildings, remains technology-driven, academic, and does not address the design strategies of spatial and behavioral thermal adaptation [13]. There is a gap between the expected energy use in newly built and constructed buildings and the real energy use [14]. The energy efficiency measures introduced in the building sector do not necessarily reduce total energy consumption. Sustainability is founded on the Trias Energetica principles that seek to limit energy use, use renewable energy sources, and make efficient use of fossil energy resources [15]. Thus, the concept is based on the continuous resource efficiency improvements due to technological progress. However, there is an overestimation of the potential saving effects due to efficiency improvements due to ignoring the behavioral responses of building users evoked by technological enhancements [16]. Several empirical studies from the 1990s and 2000s confirm the existence of the so-called "rebound effect" concerning improvements of energy efficiency in heating systems and insulation. The rebound effect of energy use is mainly due to thermal comfort standardization and the improvement of well-being [17]. Besides, the demographic transitions of the last 30 years, which led to the proliferation of bedrooms and home-based activities, have increased the expectations of privacy and personal space [18] in households. The property boom and real estate speculations were encouraged by many national taxation schemes, increasing the overall occupied surface area per capita worldwide. 
These factors highlight the remarkable influence of the behavioral responses evoked by efficiency increases and their considerable impact on energy use in renovated and newly constructed buildings.

Several studies evaluated the real energy performance and indoor thermal comfort of modern buildings before and after renovation. The study by Hens warned the scientific community about the overestimation of the real end-use savings of passive house and zeros energy buildings. It referred to the implications of the rebound effect [19]. Bourelle identified the potential contributors to the rebound effect in net-zero energy buildings [20]. Similarly did Rovers by warning about the lost energy saving potential in zero energy buildings due to rebound effects such as more heated space, higher comfort temperature, and more extended heating period [21]. Ferreira et al. assessed the benefits of renovation with a nearly-zero energy target for six buildings from Austria, Czech Republic, Denmark, Portugal, Spain, and Sweden. In their study associated with the IEA EBC Annex 56 project, they addressed policymakers and explained that promoting energy efficiency does not lead, by default, to significant energy savings [22]. However, they highlighted the social benefits of high-performance buildings such as health or fuel poverty eradication. Next, Hamburg presented a five-story nZEB renovation and showed that occupants affect energy performance goals [23]. Several reasons did not allow the nZEB performance targets to be met directly related to occupant comfort expectations [24]. Considering this overview of the literature, few studies focused on assessing the real performance of high-performance buildings concerning the rebound effect concerning thermal adaptation. This lack of knowledge highlights the importance of qualitative and quantitative post-occupancy evaluations to characterize the rebound effect impacts and the spatial and behavioral thermal adaptation of occupants in newly renovated buildings.

Therefore, this study aims to promote energy sufficiency through thermal adaptation. The objectives of the study are to (1) understand occupants' thermal behavior in nearly- and net-zero energy buildings, and (2) explore the presence of thermal adaptation (spatial and behavioral) strategies. The paper introduces evidence from real case studies on the presence and impact of a rebound effect in nearly zero-energy renovated households concerning thermal adaptation. The article provides valuable contributions to the new body of knowledge on high-performance buildings after three years of construction and occupation. The research methodology is based on a mixed-methods approach. A historical review of spatial and behavioral adaptation worldwide was first conducted. Then, 12 newly renovated dwellings were selected as case studies. Annual energy-use measurements of the existing homes (before and after renovation) were collected. In-depth interviews were conducted in 12 houses among people living in Brussels, Belgium. The study allowed for the conduction of this research using a mixed-methods approach and explored how people experience thermal comfort in their living environment. The study provides insights on occupants' spatial and behavioral thermal habits and shares some learned lessons. The literature lacks insights on the influence of occupants' thermal adaptive behavior in nearly- and net-zero energy homes; and how users can become aware of tracing the impact of their energy use and spatial exploitation of real estate. Recommendations to increase the uptake of thermal adaptation principles in design and the practice of high-performance buildings are presented.

\section{History of Space Conditioning}

In this section, we briefly present an overview of the evolution of heating and cooling technologies and thermal comfort. This section aims to identify the learned lessons from vernacular and traditional bioclimatic architecture concerning the thermal adaptation design strategy.

\subsection{Development of Heating Technology}

One of the oldest attempts to develop building heating technologies was traced back to the Greek and Roman Empire. Romans invented central heating with their hypocaust system in baths or thermae. In many heating-dominated Roman cities, the hypocaust was introduced as a system of central heating based on hot air that circulates below the floor. In the later middle ages, heating systems evolved 
to integrate animal sheds under houses as a source of heat. For example, in Northern and Central Europe, people experienced freezing conditions in households during winter. The Swedish novelist Selma Lagerlöf describes in her fiction The Emperor of Portugallia: "It was so cold that the bread froze; the cheese froze, and even the butter turned to ice. The fire itself seemed unable to hold its warmth" [25]. Only the wealthy could afford glass windows. The heat was often available in one space through fire. The living room was designed centrally to collect heat and host most occupants as long as possible during day and night. Ground floors were left for livestock to provide heat. The warmth of the animals rose through stratification and warmed the floor. Scarcity forced people to use heat rationally and concentrate the heat in central spaces while adapting their behavior accordingly.

\subsection{Development of Cooling Technology}

The idea of personal air cooling started hundreds of years ago when the Egyptians used the workforce to animate fans. However, one of the earliest examples of refined spatial and not personalized, thermal adaptation and passive cooling solutions could be found in Islamic architecture. In cooling-dominated regions, ventilative cooling, spatial thermal zoning, and air stratification were used to alter the comfort sensation. The creation of negative and positive pressure zones inside and outside buildings and air velocity could be increased to improve the comfort sensation. Also, shading and evaporative cooling were used to alter the microclimate [26-28]. Vernacular solutions such as wind catchers, courtyards, mashrabiyas, $q a^{\prime} a$, and takhtabush were physical manifestations and solutions that were translated from the principles and strategies of passive cooling [28,29]. Upper-middle-class households had different winter and summer sections designed and used depending on the season and households' orientation and configuration [26,29]. Household examples found in Damascus and Cairo show that Muslims mastered the principles of spatial thermal adaptation and landscape design to preserve coolness and moisture in buildings [5]. The creation of climate-sensitive thermal zones with central spaces to host activities and to create thermal comfort was a thermal adaptation design strategy. Spatial thermal adaptation through thermal zoning is one of the fundamental design principles of Islamic architecture [30]. This architecture is recognized for being spacy with large volumes for air stratifications and pressure control.

\subsection{Modern Heating and Cooling Technologies}

Up through about 1800, the wood-burning fireplace became the primary means of heating a household. The fireplace was the center of family life. In 1741, Benjamin Franklin improved the efficiency of the fireplace by introducing a cast-iron insert for the firebox [31]. Hearths became industrialized throughout the 1800s [32]. With the establishment of the Carrier Air Conditioning Company of America by Wills Carrier in 1902, the modern progress and evolution of HAVC systems started. In 1970, central air transformed air conditioning and ventilation systems, including condensers, coils, and fans. Heated and cooled air became present throughout homes. Thus, HVAC systems have changed the way buildings are designed and occupied. Floor plans were liberated from the thermal zones, and building users were encouraged to make use of spaces with standardized thermal conditions. With the standardization of thermal comfort, the design strategy of thermal adaptation was almost eliminated. The use of mechanical heating and cooling technologies influenced the design strategies and changed occupants' comfort expectations. With the oil crisis triggered by Arab states members of OPEC, an amplification and formalization of interest in buildings' energy efficiency occurred. However, the most effort was focused on mechanical and renewable systems with little attention to architecture and occupant behavior. Today, houses are energy neutral; and energy efficiency relies mainly on highly insulated envelopes that are airtight with highly efficient HVAC and renewable systems.

\subsection{Learned Lessons from History}

Since the 1950s, we have integrated mechanical heating and cooling systems in buildings to create universal convenience. We maintained thermal comfort automatically through control algorithms for 
thermostats to create stable indoor thermal conditions. Therefore, we pacified occupants' adaptive response to thermal comfort and abandoned the use of the thermal zoning or compartmentalization design strategy for the sake of free-dwelling plans. Before introducing energy-intensive mechanical heating and cooling systems, building designers and occupants learned to live with air and temperature fluxes adaptively $[33,34]$. Under the thermal adaptation design principles, two common design strategies were embraced in traditional architecture: (a) spatial thermal adaptation and (b) behavioral thermal adaptation. Spatial adaptive design is mainly based on thermal zoning, aiming to create buffer zones-including secured air spaces—and distinguish thermal comfort conditions in central locations in households benefiting from heat stratification. At the same time, occupants' behavior was adapted by putting on and taking off clothes or moving to other parts of the household according to daily and seasonal temperature cycles. The behavioral thermal adaptation involved cultural habits that would include changing the food or activity level through grouping to respond to the climate cycle. Today, there is a need to integrate the thermal adaptation principle in high-performance buildings and to avoid the rebound effect. The fight against climate change towards low energy communities should not only be based on technological means and solutions. We need to engage citizens to reduce the total energy use per capita for a successful energy transition. Learning from vernacular architecture can bring us closer to those goals faster.

\section{Methodology}

The methodology is based on an exploratory study that follows a mixed research approach. The study relies on the analysis and comparison of real energy use before and after renovation, along with in-depth, free-associative open-ended interviews with participants in 12 households in Brussels, Belgium. The 12 homes were selected depending on the availability of accessible energy-use data. The interviewees were contacted directly based on the list of the exemplary project provided by the Brussels-Capital Region [35].

The inclusion criteria to select the renovated buildings included buildings recently renovated (during the last five years) in compliance with the Passive House, nearly-zero energy, or net-zero energy standards requirements. Brussels was selected because it one of the exceptional cities in Europe that adopted a new ordinance that mandates compliance with the Passive House Standard requirements [36]. The regulation entered in force on 1 January 2015 and was transposed to the EPBD Directive. Through a subsidy program, owners were encouraged to renovate their buildings and transform them into high-performance buildings [35]. With the help of the Brussels Environment, a governmental body, we managed to get access to a list of renovated households. Our inclusion criteria required having gas/electricity and smart meters, solar energy systems, and heat pumps installed in the investigated buildings. The exclusion criteria for selecting the renovated buildings included having gas/electricity and smart meters, solar energy systems, and heat pumps. Also, the household tenants should not have changed the energy (gas/electricity) supplying company after renovation. Information about energy use, three years before the refurbishment, and three years after the renovation, was collected by tracing the energy bills for gas and electricity (monthly/seasonally and annually). Similar to the research of Thomsen et al. (2005), field visits and phone calls were performed to build a datasheet for every case [37]. The data collection protocol respected the General Data Protection Regulation (GDPR) guidelines developed by the European Union for anthropological research [38,39]. Finally, a list of 12 dwellings was created with a focus on energy use. The building had to be renovated after 2015 and in compliance with the Passive House standard [36].

In this research, participants were interviewed two times, each for about one hour over five weeks. Inhabitants were asked to describe the comfort conditions in every space, the functional use activities, and lifestyle in the household. Also, they had to describe the home living practices linked to energy use (heating, ventilation, lighting, use of electricity, etc.). Or thermal adaptation (cooking, eating, clothes, etc.), and identify the discrepancies between these practices and recommended technical instructions and the adaptation tactics of the inhabitants. The interviewees included seven women and 
five men; their ages ranged from 22 to 68 years. All interviewees were house owners and lived in the same building for at least seven years. Couples dominated the house composition; three households comprised a couple with two kids. The interviewed sample was not considered representative since the study sought depth and spatial-behavioral analysis.

After each interview, verbatim transcriptions were prepared. Most interviews were recorded, and handwritten notes were taken. After each consultation, a phone call was made to complete any missing information and complete a qualitative and quantitative datasheet per household. One interview was conducted in English, three in Dutch, and eight in French.

A content analysis of the interviews took place to help interpret the empirical analysis findings. The interviews were unstructured and intentionally free-associative to engage with the interviewees and remain focused (main interview questions in mind: (1) occupant spatial adaptation and (2) occupant thermal adaptation) [40]. Discussing behavioral habits is always complicated, and we wanted to avoid cliché answers to engage in rich-content narratives. Meetings took place in the participants' homes. A walk through the house took place to investigate the mechanical systems and inquire about occupancy patterns and locations. There are aspects of the methodology that present limitations. By default, the interviews generated subjective findings that can hardly be generalized. The interviewees' answers were sometimes contradictory, inconsistent, and irrational. There was a difference between the values they believed in and their actions and engagement with energy efficiency issues. However, we addressed that by avoiding bias and triangulation. We validated the interview results through handwritten memo logs created during each interview to learn from the responses. We also benefited from the prolonged engagements of spending more than two years to collect the data and interview the 12 household occupants, which allowed us to understand how they used their house and what they expected in the summer and winter seasons. Finally, we benefited from tracing the energy consumption of the renovated households over three years before and after renovation. The presence of smart meters provided high-resolution data on the monthly energy use and energy generation for each home after renovation. The characterization of the spatial use in dwellings was subjective based on personal observations [41]. The study would have generated more accurate results if occupancy sensing was performed through indoor tracking techniques in homes [42]. In this context, the occupancy study remains qualitative but still informative.

\section{Results}

In this section, we report the study findings for the 12 households based on our mixed-method approach. Figure 2 presents an example of one of the renovated nearly- and net-zero energy dwellings in Brussels. Table 1 shows further details on the energy-use measurements and calculation results, along with the critical findings of the in-depth interviews.

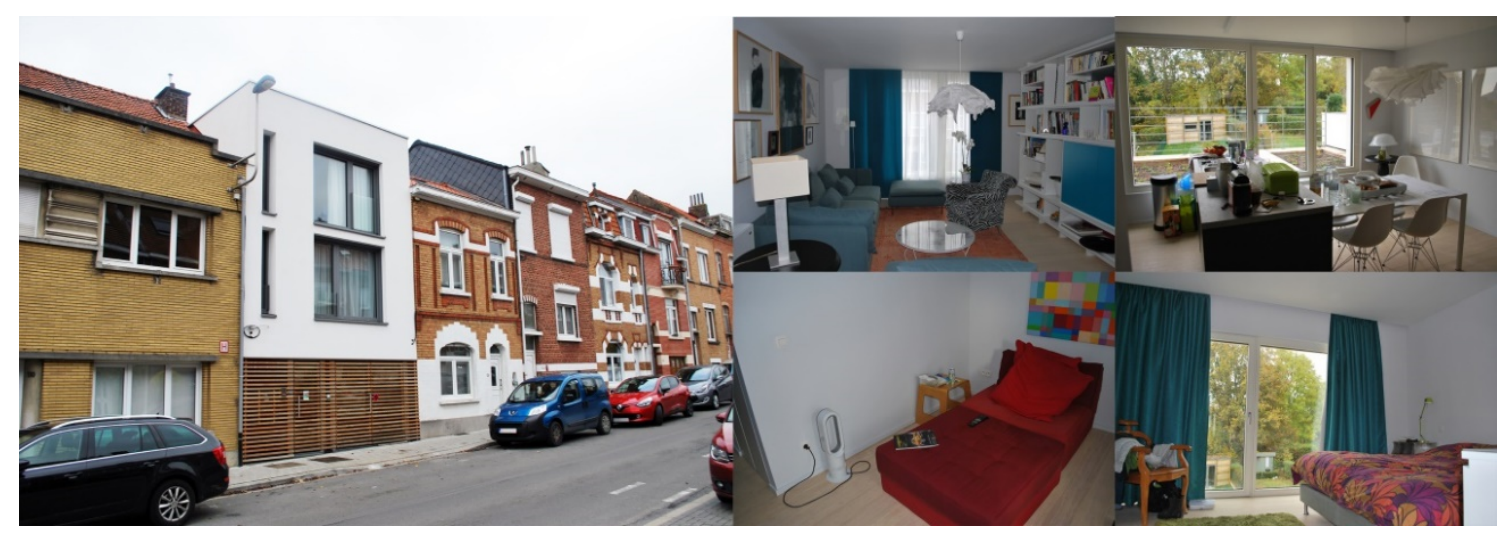

Figure 2. An example from the 12 investigated case studies (Architect: Gérard Bedoret). 
Table 1. Energy characteristics of 12 nearly- and net-zero energy case studies after renovation.

\begin{tabular}{|c|c|c|c|c|c|c|c|c|c|}
\hline ID & $\begin{array}{c}\text { Renovation } \\
\text { Date }\end{array}$ & $\begin{array}{l}\text { Surf. } \\
{[\mathrm{m} 2]}\end{array}$ & Occupant & $\begin{array}{c}\text { Total } \\
\text { Energy Use } \\
\text { Intensity } \\
{\left[\mathrm{kWh} / \mathrm{m}^{2} / \text { year }\right]}\end{array}$ & $\begin{array}{l}\text { Electricity Use } \\
\text { Intensity } \\
\text { [kWh/m²/year] }\end{array}$ & $\begin{array}{c}\text { Conductivity } \\
\text { Wall } \\
\left(\mathrm{W} / \mathrm{m}^{2} \cdot \mathrm{K}\right)\end{array}$ & $\begin{array}{l}\text { Airtightness } \\
\text { [n50/h] }\end{array}$ & $\begin{array}{l}\text { Heating } \\
\text { System }\end{array}$ & $\begin{array}{c}\text { Photovoltaic } \\
{\left[\mathrm{m}^{2}\right] / \text { Solar }} \\
\text { Thermal } \\
\text { Panels }\left[\mathrm{m}^{2}\right]\end{array}$ \\
\hline 1 & 2016 & 147 & 2 & 51 & 17 & 0.2 & 0.6 & $\mathrm{HP}^{1}$ & $15 / 4$ \\
\hline 2 & 2015 & 266 & 1 & 36 & 8 & 0.2 & 1.0 & gas boiler & $20 / 8$ \\
\hline 3 & 2013 & 279 & 2 & 35 & 12 & 0.3 & 0.8 & gas boiler & $20 / 4$ \\
\hline 4 & 2016 & 270 & 2 & 45 & 22 & 0.2 & 0.7 & gas boiler & $0 / 4$ \\
\hline 5 & 2014 & 306 & 4 & 40 & 19 & 0.4 & 0.5 & gas boiler & $0 / 8$ \\
\hline 6 & 2014 & 290 & 2 & 35 & 16 & 0.3 & 0.8 & $\mathrm{HP}^{1}$ & $0 / 4$ \\
\hline 7 & 2015 & 286 & 3 & 45 & 14 & 0.5 & 0.9 & gas boiler & $12 / 10$ \\
\hline 8 & 2015 & 306 & 2 & 43 & 28 & 0.5 & 0.8 & gas boiler & $0 / 10$ \\
\hline 9 & 2014 & 172 & 2 & 46 & 15 & 0.4 & 1.0 & $\mathrm{HP}^{1}$ & $15 / 0$ \\
\hline 10 & 2014 & 196 & 2 & 50 & 31 & 0.2 & 1.1 & gas boiler & $0 / 10$ \\
\hline 11 & 2015 & 221 & 1 & 49 & 12 & 0.3 & 0.8 & gas boiler & $12 / 4$ \\
\hline 12 & 2015 & 259 & 1 & 47 & 10 & 0.2 & 0.7 & gas boiler & $15 / 4$ \\
\hline
\end{tabular}

${ }^{1} \mathrm{HP}=$ Heat Pump.

\subsection{Calculated vs. Actual Consumption in Renovated Nearly-and Net-Zero Energy Households}

Figure 3 presents a scatter plot with the annual total energy use between 2012 and 2015 (before renovation) and 2016 and 2018 (after renovation). It represents the difference between the expected energy-use intensity (grey dots) and real energy-use intensity (black dots) after renovation. The estimated energy use is calculated by the Passive House Standard Package [36]. The two trend curves indicate a significant discrepancy between the expected energy use and the real energy use ranging between $48 \%$ and $62 \%$. The mechanical ventilation system provided air constantly during the day with a reduced air volume change during the night. The adaptive set-back strategy for mechanical ventilation and space heating seems not to bring significant savings.

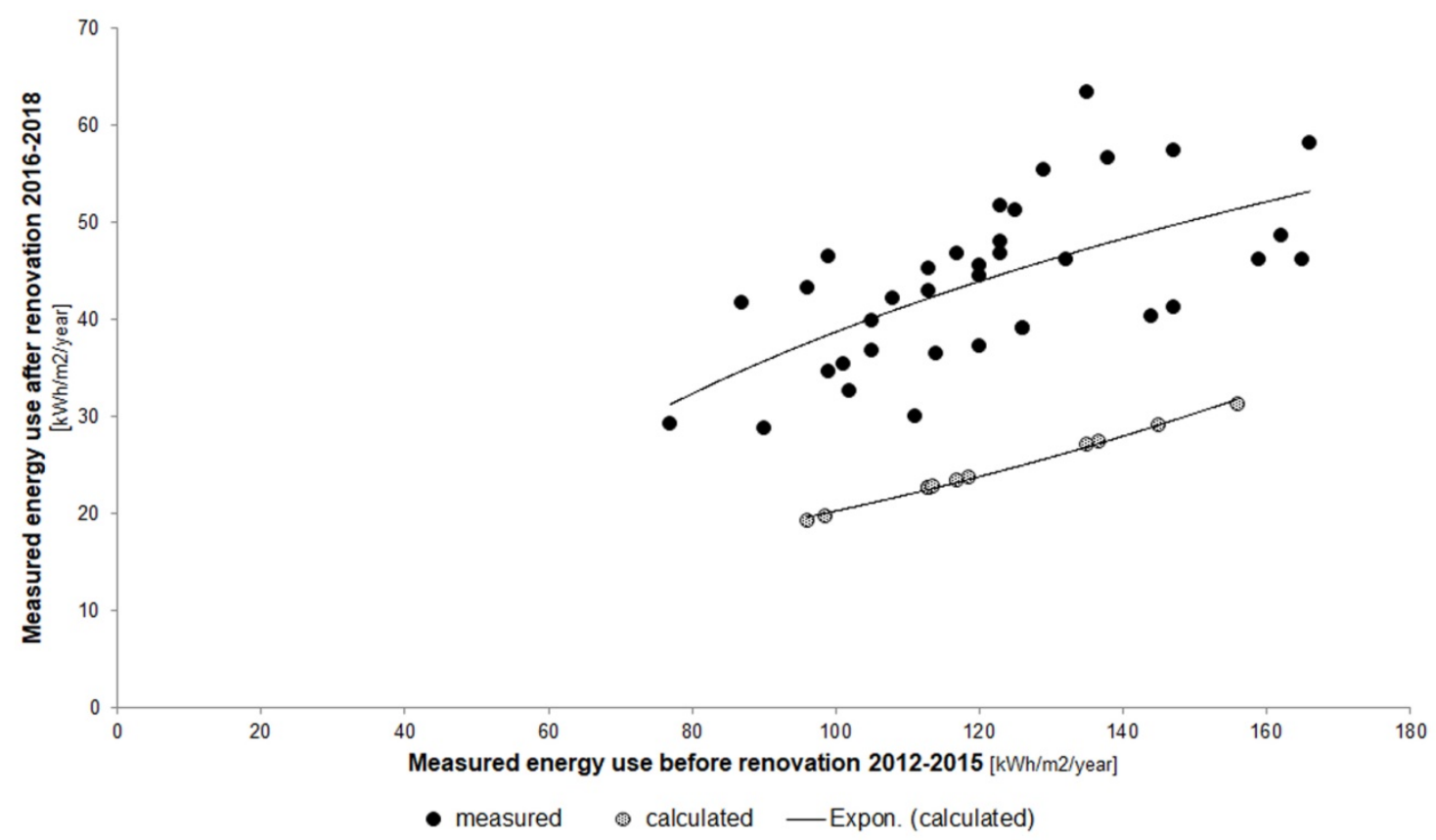

Figure 3. The upper black dots compared the energy-use intensity for the 12 nearly zero-energy households for three years before and after renovation; the lower grey dots represent the expected consumption based on the Passive House Standard calculation.

\subsection{Thermally Retrofitted Nearly and Net Zero Energy Households in Brussels}

Our analysis focused on identifying spatial and behavioral thermal adaptation measures found in the 12 investigated households. Regarding spatial thermal adaptation, none of the 12 homes had 
thermally separated zones. Figure 4a shows an example of volume continuity between the three dwelling floors without any barriers or partitions. Studies have indicated at least a $12-35 \%$ waste due to unoccupied spaces being heated [42-44]. In this case, the wasted energy use is due to the heating or ventilating of unoccupied rooms during long periods. The proportional large house space of 300 square meters for only two people makes a small fraction of the building volume occupied. In this context, designers failed to limit the households' net heated internal air volume $\left(\mathrm{m}^{3}\right)$.

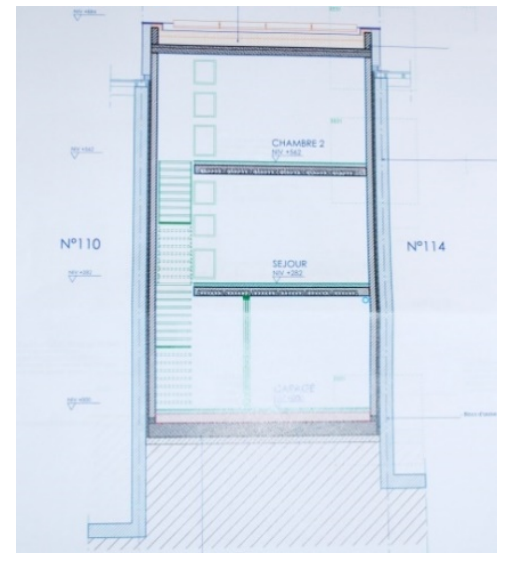

(a)

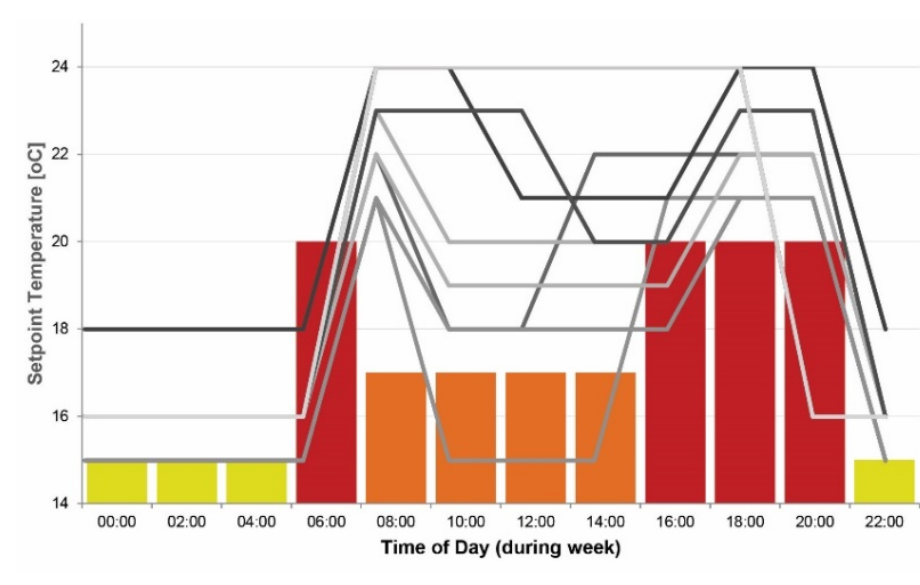

(b)

Figure 4. (a) Section in a nearly zero-energy row-house without a spatial thermal barrier between the three floors, (b). The setpoint temperature profile (lines) reported by the 12 household occupants against the ideal setpoint temperature profile (bars) for the living room.

Moreover, the interview revealed living in a high energy performance building was not the main criteria for the renovation. The idea of living in an nZEB was always considered second choice criteria. The first appreciation of occupants was mainly classical (increasing the real state value, improvement of thermal comfort, and reduction of operation cost). Homeownership is a significant part of Belgian life, with homeownership rates around $75 \%$. Before 2018, the state encouraged homeowners by offering substantial tax deductions. Therefore, many inhabitants renovated their house as a real estate investment supported by the fiscal policy [45]. Also, the interview indicated that inhabitants were aware of the energy-saving concept and environmental benefits of nZEB. Still, most of them agreed that they are caught by a busy daily life that makes thermal adaptation actions hard to take. We selected the following interview quotes as examples against thermal adaptation:

- H02 "when it's cold, we set the thermostat on 23 C, 25 C ... sometimes more."

- H09 "You just have warm spaces everywhere. (...) you can occupy any space wherever you like."

- H03 "I honestly consider myself more of a user... It is not me who will decide to heat or not heat a part of the house."

- H04 "When we come home, we change to lighter clothes; otherwise, it too warm.'

- H08 "I touch as little as possible. I am Mrs. Catastrophe."

- H12 "Most often the thermostat is in automatic mode. Sometimes, I put it in manual mode to increase the temperature for several days ..."

The quotes indicate that not all residents are identical. Still, most of them confirm their behavioral change due to the abundance and access to heated spaces in the newly renovated households. When inhabitants were asked to describe the setpoint temperature of their heating system during winter, most of them failed to imagine the schedule presented in Figure $4 \mathrm{~b}$. Besides, the occupant periods during the year varied significantly with a relatively high degree of occupancy during winter and occurrences of vacancy during summer. Simultaneously, the vacancy events during the winter appear during a short time influenced by seasonal holidays. 


\section{Discussion}

In this section, we present the key study findings and recommendations and discuss the implication of the research on the future.

\subsection{Findings}

1. The investigated households have an average of $300 \mathrm{~m}^{2}$ and an average occupancy rate of 2.4 persons/home). The result indicates a remarkably high occupied space per person and low occupancy density than the European average [5]. The 12 case studies suggest that the investigated subjects invested in spacy homes or real estate as a retirement investment.

2. The expected energy savings due to renovation only reached a $50-60 \%$ reduction compared to the original $80 \%$ reduction target. Due to improved overall comfort through better distribution of heat, the total heated volume increased. The study confirms the rebound effect of energy efficiency improvement due to the increase of setpoint temperature, increase in electricity use due to mechanical ventilation, and distribution of heat across most of the spaces of the household. A large fraction of the expected energy-use savings are used by the energy use required for ventilation and heat recovery.

3. Thermal adaptation as a design strategy and behavioral measure has almost been abandoned. Spatially, household occupants make use of more heated spaces per household compared to the pre-renovation conditions, where only two areas were intensively heated, mainly the kitchen and the living room. We could hardly identify any understanding or practice of thermal zoning design strategy or hot air stratification measures. Also, the clothing habits changed, reducing the occupants' thermal adaptation during the winter season. Several occupants admitted wearing T-shirts during winter when being at home.

4. The study confirms that building energy efficiency policies fail to address the energy-use intensity per capita and fail to engage thermal adaptation measures on the level of occupancy or spatial organization in high-performance buildings.

Since the 1970s energy crisis, the Western world opted to improve the energy efficiency of buildings through a purely technical approach. Building professionals adopted a building physics approach that focused on thermal insulation and airtightness coupled with mechanical ventilation and the use of building-integrated renewable systems. This technological approach sounds logical but resulted in more spacious dwellings with larger heated volumes. Our study confirms that in most investigated case studies, the occupants were not considered part of the solution. In this approach, the principles of vernacular architecture and bioclimatic design were reduced and became abstract, addressing only passive solar heating and passive cooling strategies. Thus, the strategy of thermal adaptation is almost neglected in most investigated cases [19].

Our study focused mainly on renovated nearly- and net-zero energy buildings. We found that the rebound effect is primarily related to the increase of heated spaces and occupant behavior. The results of our study are not new, but they add up to the pool of studies that confirm the disappointing performance of many green-certified buildings [46-49]. Most of those studies demonstrate that occupant behavior can influence energy-use intensity remarkably $[10,49,50]$. Throughout the world, there is an increase in resource use due to affluence, which results in a greenhouse gas emission increase that overpasses the reduction achieved through energy efficiency [51]. This trend is structural and is alarming because it provides evidence on the rise in total end energy use of high-performance buildings.

On the other hand, there are many design strategies for spatial adaptation and occupant thermal adaptation. The design strategies include thermal zoning, heat stratification, and occupant behavior change (clothing, food, activity, etc.) that are not encouraged by energy efficiency regulations [52]. Since the 1970s, many national energy agencies in OECD countries explicitly avoid any measures that force occupants to change their behavior or restrict their energy-use intensity, especially if they are wealthy. At the same time, homes have increased significantly in the last 50 years in many EU countries 
(see Figure 5). Having more space per person on average has implications for households' energy use and carbon footprint. The quantification of embodied carbon using the $\mathrm{kgCO}_{2} / \mathrm{m}^{2}$ metric leads us to focus on strategies such as low carbon material substitutions and not $\mathrm{kgCO}_{2} / \mathrm{m}^{2}$ metric per occupant. Worldwide, the energy efficiency of buildings is improving by $1.3 \%$ annually [53]. Simultaneously, there is an increase in the average housing floor area per person across most countries. The increase is strongly associated with ongoing income growth. Their floor area is increasing by roughly $3 \%$ per year, which is a remarkably faster rate [8]. Therefore, this approach cannot continue in the current ecological and economic crisis.

\section{Average residential floor space per capita in $\mathrm{m} 2$ (EU, 2019)}

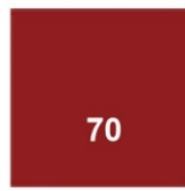

Belgium

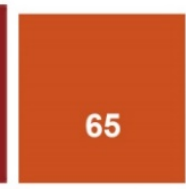

Denmark

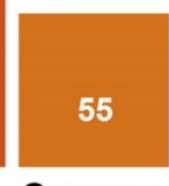

Germany

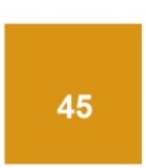

France Sweden Czechia

\section{5}

Spai
33

30

25

Figure 5. Average room space per capita for dwellings in the European Union for 2019.

\subsection{Recommendations}

Energy sufficiency actions require policy support [32]. Therefore, we recommend adopting the historical thermal adaptation principle in future energy efficiency regulations. There is a need for a structural change in thermal comfort perception and the vastly unequal energy use and carbon footprint of buildings. Occupant behavior analytic work, based on fine-grained attention to how humans strategize to achieve thermal comfort and avoid discomfort and facilitate well-being indoors, is uniquely positioned to serve and inform research in building energy efficiency sectors. We would like occupants to play a more significant role, and to adapt their behavior, to reduce the overall energy-use intensity in households. The following recommendations articulate in detail the practical advice of this study:

1. Connect the energy-use intensity to the number of occupants in a household and not to the occupied surface area of homes [54]. The 2000-watt society vision, which aims to reduce the overall average primary energy usage to no more than 2000 watts by capita, is an excellent initiative that seeks to set an upper limit of energy use per occupants in households [55]. A set of policy instruments should be developed to establish mandatory requirements that enforce the concept of an energy-use budget. An energy-use budget is the most effective way to influence occupants' behavior and stimulate them to adopt ancient behavioral thermal adaptations that include clothing, gathering, eating, and sleeping. This involves the flexibility to turn down the thermostat in unoccupied areas and set up flexible occupancy schedules.

2. Occupants should be able to control the space heating/cooling and ventilation conditions through responsive technologies. Zone-by-zone passive or active control should be introduced in all zones of households. The use of demand-controlled or presence-based ventilation/heating can play a significant role in reducing the energy use and adapting the supply for space conditioning only to occupied spaces. Dynamic sensors can play this role to ensure the comfort and air conditions and provide space heating/ventilation according to presence and need. The control of active systems should be extended to personal devices such as fans and heaters.

3. Consider spatial thermal adaptation as a critical passive and energy efficiency measure in future legislation and thermal comfort standards. Households should be designed taking "thermal zoning" and "air stratification" design strategies into account and allowing occupants to live in some zones without heating the other zones. Architects and building designers should bring spatial thermal adaptation design strategies and solutions in plans and sections. There should be 
different levels of comfort in different spaces in households for space heating/cooling systems to be effective and not just efficient. The same applies to mechanical ventilation. Interaction with the envelope (windows, solar protection devices) is an essential tool to achieve comfort passively [56]. Our findings indicate that future high-performance buildings will be dominated by electric mechanical ventilation to a certain extent. The shift towards electricity-dominated households requires a more flexible adaptation of zones heating and ventilation.

4. Encourage the development of adaptive thermal comfort models. Current standards are based on static heat balance that does not encourage spatial or behavioral adaptation. The creation of adaptive comfort standards can promote the idea of variant multizonal thermal comfort levels. The temporal and spatial nature of comfort should be reflected in new adaptive comfort standards that tolerate extended comfort limits and allow for increased and decreased comfort temperature and humidity. The effects of indoor airspeed through passive cooling or stratification through passive heating should be considered in new standards.

\subsection{Strength and Limitation}

Occupant behavior is one of the most influential variables influencing energy use in high-performance buildings [57]. This study reflects on the importance of climate-responsive design strategies that are centered on spatial and behavioral thermal adaptation. The outcomes are a revelation for scientists, building professionals, and authorities that aim to evaluate the success of their policies to promote ultra-high efficiency buildings. The Paris Agreement expects Europe to be carbon neutral by 2050. This requires a $40 \%$ carbon reduction by 2030, which is impossible. The EU is looking to push the $40 \%$ reduction threshold to $55 \%$ by 2030 . In this context, we do not need more technological approaches to reduce the energy-use intensity and carbon emission intensity of high-performance buildings. Therefore, we need mainly the engagement of citizens-through education and awareness-and the introduction of new regulations that limit energy use and assure household owners' and tenants' commitment. The spatial and behavioral thermal adaptation design strategies presented in this study are two abandoned best practices that need to be revived. In this study, we showed that the rebound effect is almost unavoidable in nearly- and net-zero energy buildings. The findings are based on the investigation of occupant behavior influence on energy use in 12 case studies located in a country that is heating dominated. The results and learned lessons can be useful and be transferred to cooling dominated climates [58].

At the same time, we recognize the limitations of our methodology. The sampling of the households is neither random nor representative. The study could have benefited from an occupancy monitoring to bring insights from quantitative observations [59]. Therefore, our findings, despite being triangulated with real monitored energy-use data, remain only relevant when explored in the context of a previous recent study $[48,54]$.

\subsection{Future Work}

We need to consider that in this study, we focused mainly on renovated buildings in Brussels, Belgium. However, the potential for energy-use increase for occupants in newly constructed buildings can be much higher. Therefore, there is a need to expand this study and increase the number of investigated households to create a more representative benchmark and reference buildings that characterize occupant behavior and energy performance in nZEB and NZEB more accurately. As we indicated earlier, there is a tendency in property owners to increase the space of households influenced by fiscal policies aiming to make more savings for retirement. Therefore, there is an artificial increase in households' total area that results in an overall increase in energy use per household. Historically, traditional buildings were designed to allow occupants to change the occupied spaces depending on the season climatic conditions. Thus, seasonality influenced the patterns of use and choice of occupied areas $[5,60]$. Our findings confirm a tendency that is happening worldwide. In many developing countries, average household sizes are decreasing as incomes increase. On the opposite, in developed 
countries, including Europe and the United States, the low occupancy rate of one or two households is associated with an increase in household size [61]. Therefore, future studies should introduce new adaptive thermal comfort models that encourage occupants to adapt their behavior and allow for personalized thermal comfort [62]. Besides, the idea of integrating thermal spatial adaptation design strategies, such as thermal zoning and compartmentation, stratification, etc., in building energy standards should be further investigated to close the energy performance gap in new constructions of nZEB and NZEB.

\section{Conclusions}

Newly constructed nearly- and net-zero energy households are oversized, energy devouring, and are used as real estate investments for retirement, above their use as energy-neutral and carbon-neutral homes. Simultaneously, the standardization of thermal comfort during the last seventy years killed any chance of thermal adaption spatially and behaviorally. However, the shift towards an energy-efficient, renewable energy-based, and climate-neutral built environment requires non-conventional measures. Vernacular architecture and adaptive human behavior are two of our most significant untapped resources for meeting the Paris Agreement and the United Nations Sustainable Development Goals. Thermal adaptation is a design strategy and lifestyle matter that makes building users central and effective towards an environmentally friendly energy transition.

Our study findings confirm the universal trend of increasing energy use of high-performance buildings. Building users invest in spacy households resulting in increased end energy use despite improved energy efficiency through renovation. The expected energy savings due to improvement only reach a $50-60 \%$ reduction compared to the original $80 \%$ reduction target. There is a demand for larger households associated with occupant expectation changes. At the same time, there is a decline of occupants per household [54].

Consequently, improving the overall comfort through a better distribution of heat, the total heated volume has increased. The study confirms the presence of the rebound effect in 12 investigated households. The rebound effect is related to the increase of setpoint temperature and distribution of heat across most of the spaces of the home. Thus, thermal adaptation has been abandoned. Spatially, household occupants make use of more heated areas per household compared to the pre-renovation conditions, where only two spaces were intensively heated, mainly the kitchen and the living room. Besides, the thermal comfort expectation and clothing habits changed, resulting in reducing the occupants' thermal adaptation during the winter season. This study contributes to the quantification of the rebound effect in renovated nearly- and net-zero energy households. The paper offers a fresh perspective on the benefits of the thermal adaptation design strategy, including thermal zoning as a non-technical solution to improve its energy efficiency. This is because we need to understand, on the deepest levels possible, the workings of human behavior in buildings. The paper presents a set of recommendations that urge policymakers and building professionals to adopt the thermal adaptation design strategy in future building energy-efficiency regulations.

Funding: This research was partially funded by the Walloon Region under the call "Actions de Recherche Concertées 2019 (ARC)" and the project OCCuPANt, on the impacts of climate change on the indoor environmental and energy performance of buildings in Belgium during summer.

Acknowledgments: The authors express their thanks to all interviewees and to the Bruxelles Environnement-Bâtiments Exemplaire program. We would also like to acknowledge the Sustainable Building Design (SBD) lab for valuable support during the interviews and the content analysis. The authors would like to gratefully acknowledge the Walloon Region and Liege University for their funding.

Conflicts of Interest: The authors declare no conflict of interest. 


\section{References}

1. Brager, G.S.; De Dear, R. Thermal adaptation in the built environment: A literature review. Energy Build. 1998, 27, 83-96. [CrossRef]

2. Shin, M.; Haberl, J.S. Thermal zoning for building HVAC design and energy simulation: A literature review. Energy Build. 2019, 203, 109429. [CrossRef]

3. Attia, S. Net Zero Energy Buildings (NZEB); Elsevier BV: Amsterdam, The Netherlands, 2018.

4. Attia, S.; Mustafa AM, E.S.; Singh, M.K. Assessment of Thermal Overheating in Free-Running Buildings in Cairo. In Proceedings of the 1st International Conference on Comfort at the Extremes: Energy, Economy and Climate, Heriot Watt University, Dubai, United Arab Emirates, 10-11 April 2019; Ecohouse Initative Ltd.: Witney, UK, 2019; pp. 902-913.

5. Heschong, L. Thermal Delight in Architecture; MIT Press: Cambridge, MA, USA, 1979.

6. Kampelis, N.; Gobakis, K.; Vagias, V.; Kolokotsa, D.; Standardi, L.; Isidori, D.; Cristalli, C.; Montagnino, F.; Paredes, F.; Muratore, P.; et al. Evaluation of the performance gap in industrial, residential \& tertiary near-Zero energy buildings. Energy Build. 2017, 148, 58-73. [CrossRef]

7. Abergel, T.; Dean, B.; Dulac, J. Global Status Report. Towards a Zero-Emission, Efficient, and Resilient Buildings and Construction Sector; International Energy Agency: Paris, France, 2017.

8. Eurostat. Average Number of Rooms per Person by Degree of Urbanization. Available online: https: //data.europa.eu/euodp/en/data/dataset/QFXgXLaCXEfW4qXuGss1gw (accessed on 25 June 2020).

9. Muresan, A.A.; Attia, S. Energy efficiency in the Romanian residential building stock: A literature review. Renew. Sustain. Energy Rev. 2017, 74, 349-363. [CrossRef]

10. Mlecnik, E.; Attia, S.G.M.; Van Loon, S. Net Zero Energy Building: A Review of Current Definitions and Definition Development in Belgium. In Proceedings of the Passive House Symposium 2011, Brussels Belgium, 7 October 2011.

11. De Meester, T.; Marique, A.-F.; De Herde, A.; Reiter, S. Impacts of occupant behaviours on residential heating consumption for detached houses in a temperate climate in the northern part of Europe. Energy Build. 2013, 57, 313-323. [CrossRef]

12. Oswald, Y.; Owen, A.; Steinberger, J.K. Large inequality in international and intranational energy footprints between income groups and across consumption categories. Nat. Energy 2020, 5, 231-239. [CrossRef]

13. Yan, D.; Hong, T.; Dong, B.; Mahdavi, A.; D'Oca, S.; Gaetani, I.; Feng, X. IEA EBC Annex 66: Definition and simulation of occupant behavior in buildings. Energy Build. 2017, 156, 258-270. [CrossRef]

14. De Wilde, P. The gap between predicted and measured energy performance of buildings: A framework for investigation. Autom. Constr. 2014, 41, 40-49. [CrossRef]

15. Attia, S. Regenerative and Positive Impact Architecture; Springer Science and Business Media LLC: Berlin/Heidelberg, Germany, 2018.

16. Binswanger, M. Technological progress and sustainable development: What about the rebound effect? Ecol. Econ. 2001, 36, 119-132. [CrossRef]

17. Boulanger, P.; Couder, J.; Marenne, Y. Household Energy Consumption and Rebound Effect (Belgian Science Policy); Federal Science Policy: Brussels, Belgium, 2013.

18. Yang, L.; Yan, H.; Lam, J.C. Thermal comfort and building energy consumption implications-A review. Appl. Energy 2014, 115, 164-173. [CrossRef]

19. Hens, H. Energy efficient retrofit of an end of the row house: Confronting predictions with long-term measurements. Energy Build. 2010, 42, 1939-1947. [CrossRef]

20. Bourrelle, J.S. Zero energy buildings and the rebound effect: A solution to the paradox of energy efficiency? Energy Build. 2014, 84, 633-640. [CrossRef]

21. Rovers, R. Zero-Energy and Beyond: A Paradigm Shift in Assessment. Buildings 2014, 5, 1-13. [CrossRef]

22. Ferreira, M.; Almeida, M.; Rodrigues, A. Impact of co-benefits on the assessment of energy related building renovation with a nearly-zero energy target. Energy Build. 2017, 152, 587-601. [CrossRef]

23. Hamburg, A.; Kuusk, K.; Mikola, A.; Kalamees, T. Realisation of energy performance targets of an old apartment building renovated to nZEB. Energy 2020, 194, 116874. [CrossRef]

24. Thomas, S.; Brischke, L.A.; Thema, J.; Kopatz, M. Energy Sufficiency Policy: An Evolutionof Energy Efficiency Policy or Radically New Approaches? ECEEE Proc.: Toulon, France, 2015; pp. 1-6.

25. Lagerlöf, S. Kejsarn av Portugallien en Värmlandsberättelse; Bonnier: Winter Park, FL, USA, 1918. 
26. Attia, S. The role of Landscape Design in Improving the Microclimate in Traditional Courtyard Buildings in Hot Arid Climates. In Proceedings of the 23rd International Conference on Passive and Low Energy Architecture-PLEA, Geneva, Switzerland, 6-8 September 2006; pp. 22-24.

27. Mossad, G.; Ezzat, H.; Talaat, N. Natural ventilation in old islamic houses the study of courtyard in old cairo case study. J. Al-Azhar Univ. Eng. Sect. 2016, 11, 601-615. [CrossRef]

28. Ficarelli, L. Passive Cooling in Traditional Construction: Case of Domestic Architecture in Egypt. In Proceedings of the SAUD 2010 Conference Sustainable Architecture and Urban Development, Amman, Jordan, 12-14 July 2010.

29. Mohamed, M.A. The mastery of the Takhtabush as a paradigm traditional design element in the hot zone climate. EQA Int. J. Environ. Qual. 2018, 28, 1-11.

30. Al-Hinai, H.; Batty, W.; Probert, S. Vernacular architecture of Oman: Features that enhance thermal comfort achieved within buildings. Appl. Energy 1993, 44, 233-258. [CrossRef]

31. Tolles, F.B. The Papers of Benjamin Franklin; Europ. Council for an Energy Efficient Economy: Stockholm, Sweden, 1964; Volume 2-6.

32. Ionescu, C.; Baracu, T.; Vlad, G.-E.; Necula, H.; Badea, A. The historical evolution of the energy efficient buildings. Renew. Sustain. Energy Rev. 2015, 49, 243-253. [CrossRef]

33. Mahdavi, A.; Kumar, S. Implications of indoor climate control for comfort, energy and environment. Energy Build. 1996, 24, 167-177. [CrossRef]

34. Beall, C.M.; Jablonski, N.G.; Steegmann, A.T. Human Adaptation to Climate: Temperature, Ultraviolet Radiation, and Altitude; Wiley: Hoboken, NJ, USA, 2012; pp. 175-250.

35. BE. Vous Cherchez un Projet Batex. Environnement Brussels. Available online: https:/environnement.brussels/ thematiques/batiment-et-energie/bonnes-pratiques-pour-construire-et-renover/sinspirer-des-batiments (accessed on 25 July 2020).

36. Feist, W.; Pfluger, R.; Kaufmann, B.; Schnieders, J.; Kah, O. Passive House Planning Package 2007. In Specifications for Quality Approved Passive Houses, Technical Information PHI-2007/1 (E); Passivhaus Institut: Darmstadt, Germany, 2007.

37. Thomsen, K.E.; Schultz, J.M.; Poel, B. Measured performance of 12 demonstration projects-IEA Task 13 advanced solar low energy buildings. Energy Build. 2005, 37, 111-119. [CrossRef]

38. Voigt, P.; Bussche, A.V.D. The EU General Data Protection Regulation (GDPR); Springer Science and Business Media LLC: Berlin/Heidelberg, Germany, 2017.

39. De Koning, M.; Meyer, B.; Moors, A.; Pels, P. Guidelines for anthropological research: Data management, ethics, and integrity. Ethnography 2019, 20, 170-174. [CrossRef]

40. Attia, S. In-depth Interviews, IFRES, Liege University, Belgium, Brussels. Available online: https://tinyurl. com/ycacmljt (accessed on 1 September 2020).

41. Attia, S. Observation E Ethnography Research; IFRES, Liege University: Belgium, Brussels, 2020; Available online: https://tinyurl.com/y8takwrv (accessed on 1 September 2020).

42. Van Loy, N.; Verbeeck, G.; Knapen, E. High accuracy indoor positioning system to monitor spatial use in dwellings. Measur. Behav. 2018, 2, 4-10.

43. Pitts, A.; Bin Saleh, J. Potential for energy saving in building transition spaces. Energy Build. 2007, 39, 815-822. [CrossRef]

44. Singh, M.K.; Attia, S.; Mahapatra, S.; Teller, J. Assessment of thermal comfort in existing pre-1945 residential building stock. Energy 2016, 98, 122-134. [CrossRef]

45. Verbeeck, G. Property Taxation as a Policy Instrument to Steer Energy Efficiency and Sustainable Land Use: A Review. In Proceedings of the ECEEE Summer Study, Belambra Presqu'île de Giens, France, 3-8 June 2019.

46. Attia, S.; Shadmanfar, N.; Ricci, F. Developing two benchmark models for nearly zero energy schools. Appl. Energy 2020, 263, 114614. [CrossRef]

47. Newsham, G.R.; Mancini, S.; Birt, B.J. Do LEED-certified buildings save energy? Yes, but ... . Energy Build. 2009, 41, 897-905. [CrossRef]

48. Hu, S.; Yan, D.; Azar, E.; Guo, F. A systematic review of occupant behavior in building energy policy. Build. Environ. 2020, 175, 106807. [CrossRef]

49. Santin, O.G. Occupant behaviour in energy efficient dwellings: Evidence of a rebound effect. Neth. J. Hous. Environ. Res. 2012, 28, 311-327. [CrossRef] 
50. Santin, O.G.; Itard, L.; Visscher, H. The effect of occupancy and building characteristics on energy use for space and water heating in Dutch residential stock. Energy Build. 2009, 41, 1223-1232. [CrossRef]

51. Wiedmann, T.; Lenzen, M.; Keyßer, L.T.; Steinberger, J.K. Scientists' warning on affluence. Nat. Commun. 2020, 11, 1-10. [CrossRef] [PubMed]

52. Wilson, L. How Big Is a House. Shrink That Footprint. 2020. Available online: http://shrinkthatfootprint. com/how-big-is-a-house (accessed on 15 September 2020).

53. IEA. Building Energy Performance Metrics: Supporting Energy Efficiency Progress in Major Economies; IEA: Paris, France, 2015.

54. O'Brien, W.; Gaetani, I.; Carlucci, S.; Hoes, P.-J.; Hensen, J. On occupant-centric building performance metrics. Build. Environ. 2017, 122, 373-385. [CrossRef]

55. Fink, A.M.; Stulz, R.J. 2000 W society: A sustainable Energy Vision for the Future. In Proceedings of the Institution of Civil Engineers-Engineering Sustainability; Thomas Telford Ltd.: London, UK, 2012; Volume 165, pp. 255-260.

56. Marín-Restrepo, L.; Trebilcock, M.; Gillott, M. Occupant action patterns regarding spatial and human factors in office environments. Energy Build. 2020, 214, 109889. [CrossRef]

57. Guerra-Santin, O.; Itard, L. Occupants' behaviour: Determinants and effects on residential heating consumption. Build. Res. Inf. 2010, 38, 318-338. [CrossRef]

58. Ramos, G.; Lamberts, R.; Abrahão, K.C.F.J.; Bandeira, F.B.; Teixeira, C.F.B.; De Lima, M.B.; Broday, E.E.; Castro, A.P.A.S.; Leal, L.D.Q.; De Vecchi, R.; et al. Adaptive behaviour and air conditioning use in Brazilian residential buildings. Build. Res. Inf. 2020, 1-16. [CrossRef]

59. Calì, D.; Matthes, P.; Huchtemann, K.; Streblow, R.; Müller, D. CO 2 based occupancy detection algorithm: Experimental analysis and validation for office and residential buildings. Build. Environ. 2015, 86, 39-49. [CrossRef]

60. Pereira, P.F.; Ramos, N.M.M. Occupant behaviour motivations in the residential context-An investigation of variation patterns and seasonality effect. Build. Environ. 2019, 148, 535-546. [CrossRef]

61. IEA. Market Report Series: Energy Efficiency; International Energy Agency: Paris, France, 2019.

62. Pérez-Fargallo, A.; Pulido-Arcas, J.; Rubio-Bellido, C.; Trebilcock, M.; Piderit-Moreno, M.B.; Attia, S. Development of a new adaptive comfort model for low income housing in the central-south of chile. Energy Build. 2018, 178, 94-106. [CrossRef] 